\title{
Complex Buckling Instability Patterns of Nanomembranes with Encapsulated Gold Nanoparticle Arrays
}

Chaoyang Jiang, Srikanth Singamaneni, Emily Merrick, and Vladimir V. Tsukruk ${ }^{*}$

\section{Supporting information}

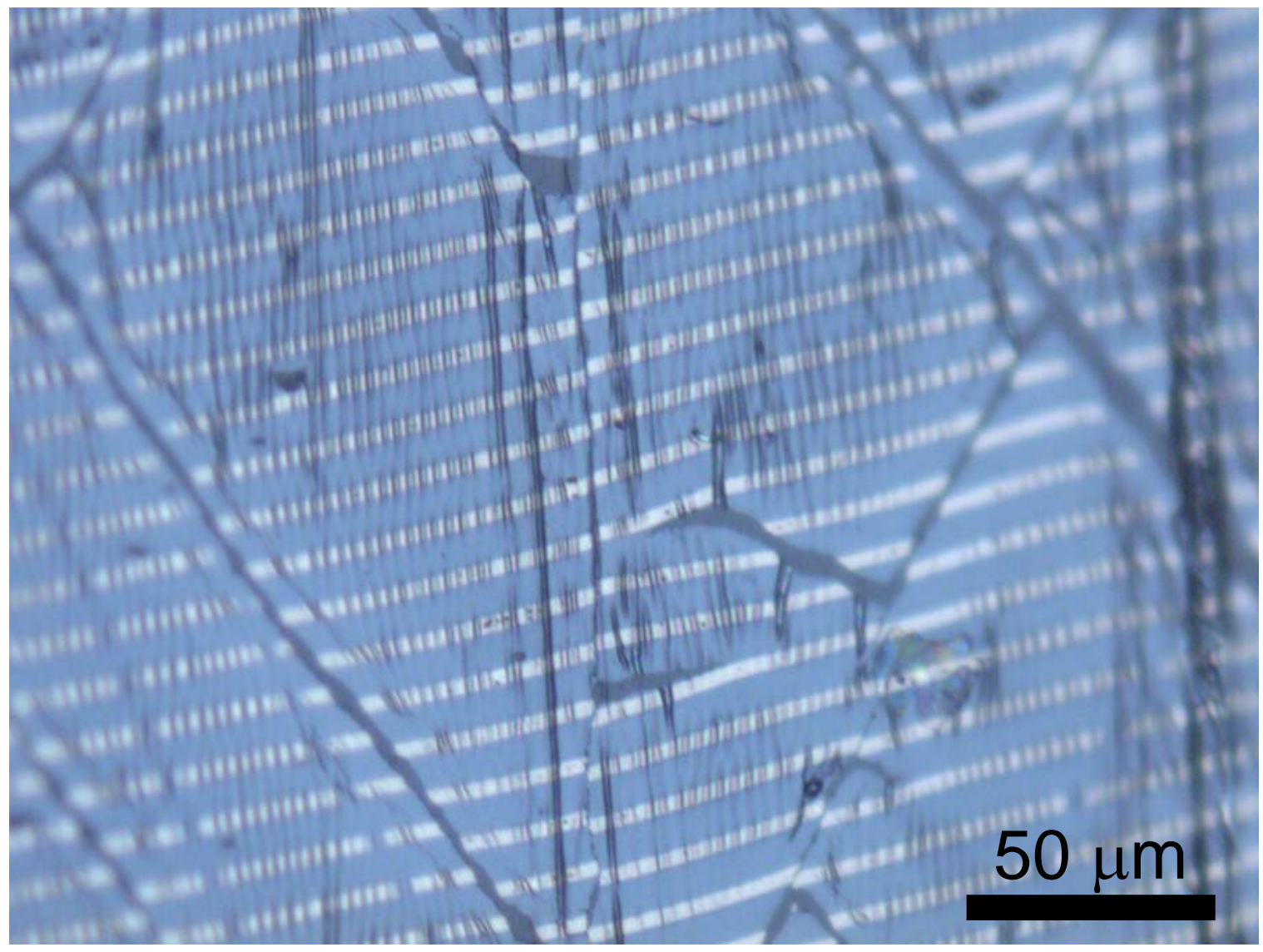

Optical image of compressed micropatterned LbL films. The buckling patterns can be easily observed. Near the edges of the defects and cracks, buckling patterns are less pronounced. 

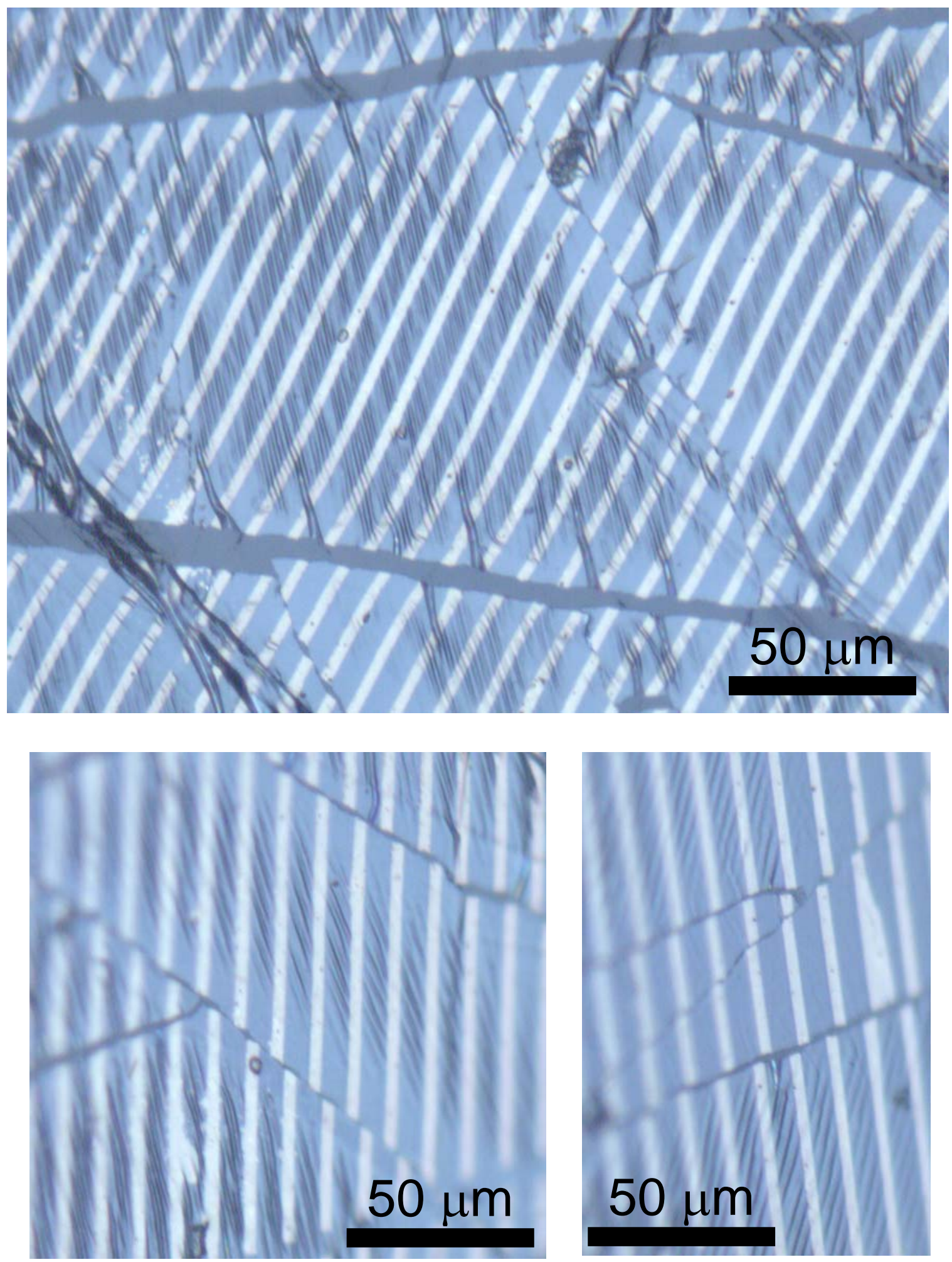

Additional optical images of compressed micropatterned LbL films. Near the edges of the cracks, there are no buckling patterns obtained due to the stress release,. 

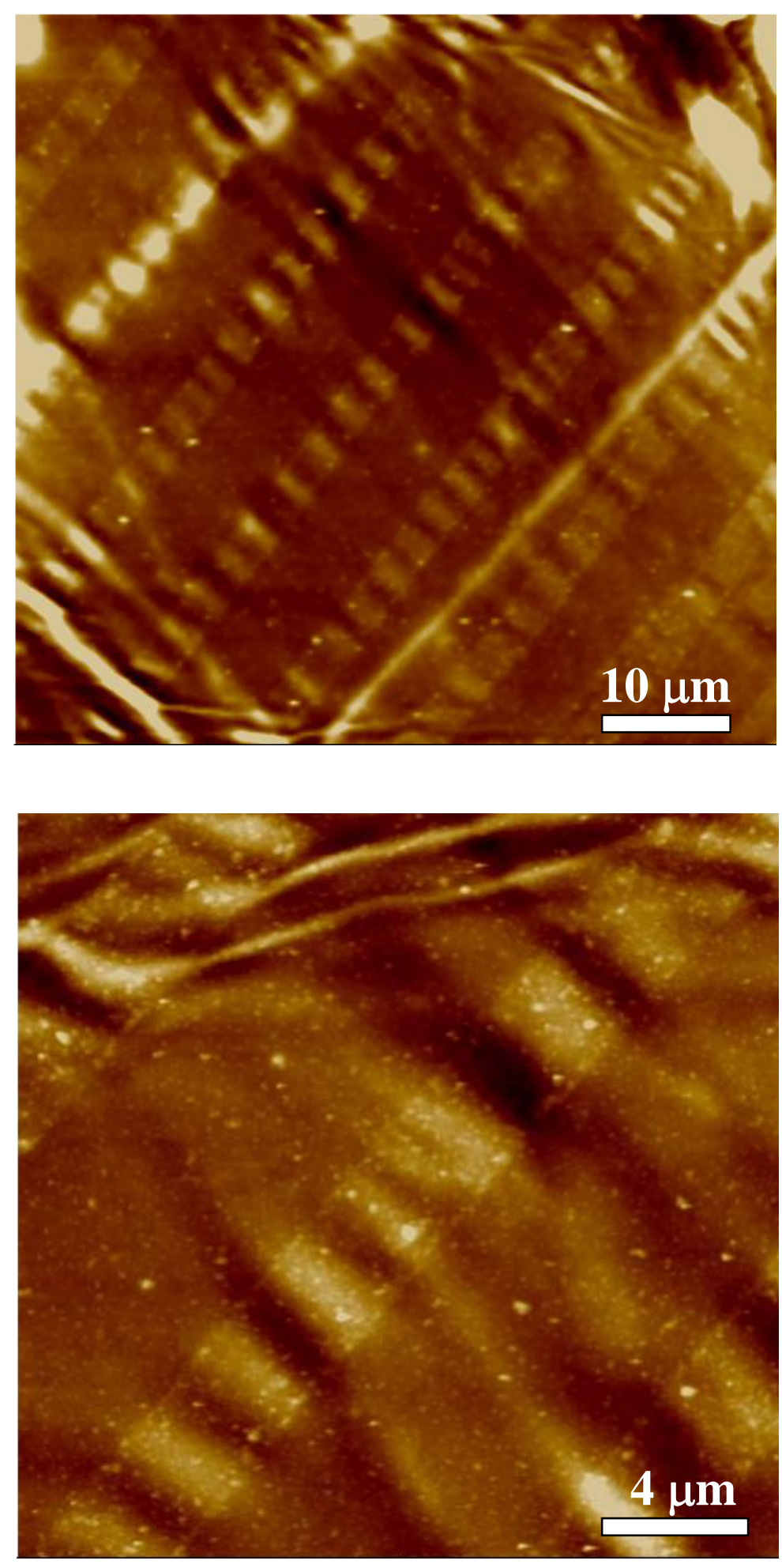

AFM images of buckling patterns at low strain. Z scale for both images: $200 \mathrm{~nm}$. 